\title{
Interactive comment on "The impact of mineral dust on the day-to-day variability of stratiform cloud glaciation occurrence" by Diego Villanueva et al.
}

\section{Anonymous Referee \#3}

Received and published: 12 December 2018

\section{General comments:}

The manuscript presents an interesting study of mineral dust impacts on stratiform cloud glaciation occurrence using satellite remote sensing measurements and MACC aerosol reanalysis daily product. Mineral dust is one of the major atmospheric aerosols and are also efficient INPs. However, it is still challenging to quantify their impacts on ice nucleation in clouds and cloud thermodynamic phase partitioning. Their findings in this study confirm that mineral dust has positive correlations with ice cloud occurrence on a global scale even after limiting other impact factors. The approach presented in this study is very unique. Personally, I like the approach and also am very happy with 
their findings. However, many of their discussions are hard to explain the observed features (sometimes contradict with previous studies). Besides, the manuscript is not well organized and poorly written (especially the comparisons between FPRDARDAR and FPRGOCCP) and therefore is hard to read. Overall, I believe serious revisions are needed before the manuscript be accepted by ACP.

Major comments:

Fig1.: 1) About the sample size, what causes the missing datapoints? 2) Why do the high-latitudes have less datapoints than the mid-latitudes? 3) Is the sample size same or similar for DARDAR and MACC?

Fig 2. and related discussion: 1) According to line 143-144 and line 153, "lidar-not-fullyattenuated" and "only ice pixels are considered as ice clouds", I would expect basically DARDAR and GOCCP have very similar FPR. For example, in Fig 2., DARDAR detected the ice virga below the liquid layer top. However, generally, the liquid layer at the top will fully attenuate the lidar signal (also as stated in line 119). Therefore, given the filters listed in line 143-144, I do not understand why DARDAR still show an ice layer below; 2) Comparing $2 \mathrm{a}, \mathrm{b}, \mathrm{d}$, e, and $\mathrm{f}$ there are not clouds at latitudes between -40 and -45 and temperatures between -6 and 3 , there shows no cloud in $2 a$, b, and e, but does have FPRDARDAR and FPRGOCCP in $2 \mathrm{~d}$ and $\mathrm{f}$, what's the reason for the differences? 3) Comparing $2 d$ and e, at latitudes between -40 and -45 , the whole profiles shows ice cloud in $2 \mathrm{~d}$ but it is liquid in figure $2 \mathrm{e}$. Even with all the rules described in line 157-158, it is still difficult to understand why it is liquid in figure $2 e$ (the grid box is still $1.875 \times 1.875$, right?)

Fig.3: 1) I really object to put dust mixing ratio in this figure. There is no physical relationship between dust mixing-ratio and temperature. Dust mixing ratio decreases with height near the source region and temperature generally decrease with height in the atmosphere. But physically, there is no relationship between temperature and dust! 2) In line 235, "mixing-ratios are higher near the surface than at high altitudes", this is not

Printer-friendly version

Discussion paper
Interactive

comment 
true for transported dust layer such as over the high latitude regions. Overall, this study is trying to look at the relationship between pure ice cloud fractions and dust mixing ratios. Therefore, comparing FPRDARDAR and FPRGOCCP has little contribution to the main research topic in this study and the descriptions of converting different FPRs are quite confusing and distracting. In fact, in the proceeding sections, only FPRGOCCP is used most of the time. Therefore, I would suggest just use FPRGOCCP in the study.

Fig. 4: 1) It is surprising that 'maximum of FPR is located near the Equator'. Kanitz et al. (2011) showed that Northern mid-latitudes have much higher ice-containing cloud fraction than the tropical regions. Do the authors have speculations why the results are so different? Line 251, what's the reason for the steep increase of FPR at 840? 2) Does this steep increase of FPR only occur at -15 C? How about at $-20,-25$ C? 3) Line 254 , do the referred studies also comparing the fraction of ice clouds at the same temperature? It is really hard to explain why southern polar regions have higher FPR than the northern at a given temperature. Also, at $-30 \mathrm{oC}$, the southern polar regions have much lower FPR than the northern, which contradicts with the two referred papers. 4) Line 255, I do not see any downdrafts (negative values I guess) in the figure. 5) Line 258 , again, it is hard to understand why updraft positively correlated to the occurrence of ice clouds at $-20 \mathrm{oC}$. The referred paper is looking at large scale motion impacts on supercooled liquid fraction. Generally strong updrafts have higher supersaturation and lead to the more liquid formation, and downdrafts cause liquid layer to evaporate, and thus impact the supercooled liquid fraction, which makes sense. I have difficulty to figure out the physical process that updraft velocity lead to the occurrence of ice cloud at -20 oC given that deposition ice nucleation is rare in the atmosphere.

Figure 8 and Line 390: 1) RH has strong impacts on ice nucleation only for the deposition mode. While at the temperatures between -40 and $0 \mathrm{oC}$, ice particles are always formed from the freezing of liquid droplets in the atmosphere. Therefore, I do not think it is necessary to include the discussion of $\mathrm{RH}$ relationship with dust. In another word, large-scale motion has strong impacts on cloud thermodynamic phase partition, mainly

Interactive comment
Printer-friendly version

Discussion paper 
on the formation and evaporation of liquid droplets, but it has little impacts on ice nucleation at the heterogeneous temperature range; 2) Please explain why dust aerosol mixing-ratio increases with isotherm height; 3 ) Why there are not downdraft?

Minor comments:

"CLOUDAT" -> CloudSat.

Line 120: "obtaining good results". How good are the simulated dust mixing-ratios compared with observations?

Line 125: Jan'0 -> Jan'09

Line 138 and 140: the word 'pixel' is confusing. How does pixel be defined in this study? Is this a layer bin in each lidar or radar profile? Then how to know whether a pixel is precipitating or not?

Line 164: how is cloud volume fraction derived? What's the benefit using this cloud volume fraction comparing FPR?

Line 182 and equation 3.1: How is equation 3.1 is derived or why does this definition differentiate the clear sky and liquid phase condition?

Line 241: It is not a good starting sentence, and should be put behind Line 243.

Line 320: Any guess of the common mechanism?

Figure 6: Given similar dust mixing-ratio at $-15 \mathrm{oC}$, the ice occurrence is $\sim 10 \%$ higher at mid-latitudes than polar regions, what's the reason?

Figure 7: at $-30 \mathrm{oC}$, ice occurrence shows little correlations with dust, but rather has dramatic latitude differences. Any speculations of the reason? I guess at such colder temperatures, other aerosol particles such as soot are also good INPs. It might be interesting to also look at the relationships between FRP and soot particles.

References: Kanitz,ÂăT.,ÂăP. Seifert,ÂăA. Ansmann,ÂăR. Engelmann,ÂăD. Al- 
thausen,ÂăC. Casiccia, andÂăE. G. Rohwer (2011),ÂăContrasting the impact of aerosols at northern and southern midlatitudes on heterogeneous ice formation,ÂăGeophys. Res. Lett.,Âă38, L17802, doi:Âă10.1029/2011GL048532.

Interactive comment on Atmos. Chem. Phys. Discuss., https://doi.org/10.5194/acp-2018-1074, 2018.

Interactive

comment 